\title{
Hysteroscopic removal of retained products of conception: historic approach or new iteration?
}

\author{
Usha Verma, Frank A. Crespo \\ University of Miami, Jackson Memorial Hospital, Miami, FL, USA \\ Correspondence to: Usha Verma. University of Miami, Jackson Memorial Hospital, Miami, FL, USA. Email: Uverma@med.miami.edu. \\ Comment on: Zhang A, Huang H, Qin X, et al. Hysteroscopic removal of angular retained products of conception hidden behind intrauterine \\ adhesions using a 12-Fr spoon-shaped forceps. Ann Transl Med 2020;8:59.
}

Submitted Mar 10, 2020. Accepted for publication Jul 01, 2020.

doi: 10.21037/atm-2020-119

View this article at: http://dx.doi.org/10.21037/atm-2020-119

Hysteroscopy has long been a gynecologist's tool for minimally invasive diagnosis and treatment of intrauterine pathology. Its use can run the gamut from direct visualization to operative removal of polyps and fibroids. Some other uses of hysteroscopy include removal of intrauterine devices, management of intrauterine adhesions (IUA), and removal of retained products of conception (RPOC). It remains a mainstay in the field of gynecology due to its minimal complications, cost effectiveness, and short procedural time (1).

This case report addresses hysteroscopic removal of RPOC using a 12-Fr spoon-shaped forceps. A 34 years old woman, who presented with abnormal menses 4 months after evacuated first trimester RPOC, was the subject of the study. Transvaginal ultrasound showed left angular RPOC along with IUA. After insertion of the hysteroscope, blunt adhesiolysis was performed using the 5-Fr spoonshaped forceps, followed by dissection with cold scissors. This technique was also reported by Huang et al. as a method of adhesiolysis to better protect the endometrium, compared to resectoscopic techniques (2). The RPOC were then identified and removed with the 12-Fr spoon-shaped forceps. This procedure was performed under ultrasound guidance. A 12-Foley catheter was subsequently inserted into the uterine cavity and left inside for 2 weeks. The patient went home on hormonal therapy, estradiol $3 \mathrm{mg}$ BID for 28 days, and progesterone $200 \mathrm{mg}$ was added for the last 6 days. A follow-up hysteroscopy, 1 month later, revealed an almost normal uterine cavity (3).

Hysteroscopy remains the treatment of choice for IUA or Asherman's syndrome. Unlike blind curettage, hysteroscopy directly visualizes adhesions and allows for a more complete and safe removal of adhesions. Both blunt and sharp dissection techniques have been used for lysis of adhesions in gynecologic surgery. As seen in this case report, when pathology is severe and uterine landmarks are obscured, hysteroscopic lysis of adhesions can be performed under ultrasound guidance or laparoscopy to decrease the risk of uterine perforation. An established method to prevent reformation of adhesions, as used by Zhang et al. in this case report, involves inserting an intrauterine balloon catheter to separate the opposing layers of the endometrium. It is also common practice to send patients home on a conjugated estrogen for 4 weeks to promote re-epithelialization, followed by adding a progestin the last week; however, the effectiveness of this method has not been established (4).

Fertility outcomes have been shown to be comparable when using Sodium hyaluronate and carboxymethylcellulose versus a foley catheter for adhesion prophylaxis (5). In this case report, both methods were used, as the top portion of the foley catheter was removed to insert hyaluronic acid gel into the uterine cavity. This case report is comparable to other studies in that it proves that hysteroscopic removal of RPOC is safe and effective. In fact, incomplete evacuation of RPOC has only been shown to be $1 \%$ in cases treated by hysteroscopy versus $29 \%$ by curettage (6).

Although not directly addressed in this study, the management of RPOC should always be based on patient presentation. A patient with RPOC can be managed either expectantly, medically, or surgically depending on her signs and symptoms. A surgical approach would be more fitting in a patient who is actively bleeding or has signs of infection. For patients who are hemodynamically stable with no active bleeding, expectant management or medical management is appropriate. In one study, two $800 \mathrm{mg}$ doses of vaginal 
misoprostol could completely evacuate the uterus in $80 \%$ of subjects with a first trimester missed abortion (7). Compared to curettage, hysteroscopic removal of RPOC is more precise, as it allows for direct visualization of tissue removal.

This case report is consistent with previous literature on RPOC. Being a case report, its scope and generalizability is limited. There are several disadvantages of operative hysteroscopy that were not addressed such as fluid management. Depending on the distention media used, a maximum fluid deficit should not be exceeded. In more complicated cases, such as those with dense adhesions, attention should be made not to exceed a $2,500 \mathrm{~mL}$ fluid deficit, if using normal saline. One of the strengths of this paper is that it describes the use of a 12-Fr spoon-shaped forceps to remove RPOC in the presence of adhesions. The authors state that previous literature only addresses removal of RPOC using electrical instruments and curettage. They also emphasize the safety of this approach for angular RPOC. However, this procedure occurred under ultrasound guidance, thus making it difficult to distinguish its safety from a curettage also performed under ultrasound guidance.

Hysteroscopy is a known treatment modality for RPOC. Compared to blind curettage, hysteroscopy has been shown to have lower rates of IUA and higher rates of subsequent pregnancies (8). Just as used in removal of foreign bodies, hysteroscopy can aid in providing a precise removal of tissue under direct visualization. This case report combines known treatment for IUA, followed by removal of RPOC with a 12-Fr spoon-shaped forceps. More studies are needed to delineate the safest and most effective instrument for removal of RPOC.

\section{Acknowledgments}

Funding: None.

\section{Footnote}

Provenance and Peer Review: This article was commissioned by the editorial office, Annals of Translational Medicine. The article did not undergo external peer review.

Conflicts of Interest: Both authors have completed the ICMJE uniform disclosure form (available at http://dx.doi. org/10.21037/atm-2020-119). Both authors have no conflicts of interests to declare.

Ethical Statement: The authors are accountable for all aspects of the work in ensuring that questions related to the accuracy or integrity of any part of the work are appropriately investigated and resolved.

Open Access Statement: This is an Open Access article distributed in accordance with the Creative Commons Attribution-NonCommercial-NoDerivs 4.0 International License (CC BY-NC-ND 4.0), which permits the noncommercial replication and distribution of the article with the strict proviso that no changes or edits are made and the original work is properly cited (including links to both the formal publication through the relevant DOI and the license). See: https://creativecommons.org/licenses/by-nc-nd/4.0/.

\section{References}

1. The Use of Hysteroscopy for the Diagnosis and Treatment of Intrauterine Pathology: ACOG Committee Opinion, Number 800. Obstet Gynecol 2020;135:e138-e148.

2. Huang H, Cheng C, Johnson G, et al. Hysteroscopic Intrauterine Adhesiolysis Using a Blunt Spreading Dissection Technique With Double-action Forceps. J Minim Invasive Gynecol 2018;25:583-4.

3. Zhang A, Huang H, Qin X, et al. Hysteroscopic removal of angular retained products of conception hidden behind intrauterine adhesions using a 12-Fr spoon-shaped forceps. Ann Transl Med 2020;8:59.

4. Fritz MA, Speroff L. Clinical Gynecologic Endocrinology And Infertility. 8th ed; LWW, 2011:1176-1204.

5. Chappell N, Bates G, Mclaren J. Reproductive Outcomes After Operative Hysteroscopy Using Sodium Hyaluronate and Carboxymethylcellulose. Obstet Gynecol 2014;188S. doi: 10.1097/01.AOG.0000447213.68077.9c.

6. Hooker AB, Aydin H, Brölmann HA, et al. Longterm complications and reproductive outcome after the management of retained products of conception: a systematic review. Fertil Steril 2016;105:156-64.e642.

7. Wood S, Brain P. Medical Management of Missed Abortion. Obstet Gynecol 2002;99:563-6.

8. Smorgick N, Barel O, Fuchs N, et al. Hysteroscopic management of retained products of conception: metaanalysis and literature review. Eur J Obstet Gynecol Reprod Biol 2014;173:19-22.

Cite this article as: Verma U, Crespo FA. Hysteroscopic removal of retained products of conception: historic approach or new iteration? Ann Transl Med 2020;8(19):1210. doi: 10.21037/atm-2020-119 